\title{
Benzopyrazines: Synthesis, Characterization and Evaluation as Aldose Reductase Inhibitors
}

\author{
Huma Aslam Bhatti ${ }^{1, ~ *}$, Qurat-Ul-Ain Zaheer ${ }^{1}$, Yildiz Tehseen ${ }^{2}$, Zahid Shaiq ${ }^{3}$, \\ Khalid Mohammed Khan ${ }^{1}$, Abdul Hameed ${ }^{1}$, Jamshed Iqbal ${ }^{1}$ \\ ${ }^{1}$ Hussian Ebrahim Jamal Research Institute of Chemistry, International Center for Chemical and Biological Sciences, University of Karachi, \\ Karachi, Pakistan \\ ${ }^{2}$ Centre for Advanced Drug Research, COMSATS Institute of Information Technology, Abbottabad, Pakistan \\ ${ }^{3}$ Institute of Chemical Sciences, Bahauddin Zakariya University, Multan, Pakistan
}

Email address:

huma_aslam31@hotmail.com (H. A. Bhatti)

*Corresponding author

\section{To cite this article:}

Huma Aslam Bhatti, Qurat-Ul-Ain Zaheer, Yildiz Tehseen, Zahid Shaiq, Khalid Mohammed Khan, Abdul Hameed, Jamshed Iqbal. Benzopyrazines: Synthesis, Characterization and Evaluation as Aldose Reductase Inhibitors. Science Journal of Chemistry. Special Issue: Benzopyrazines: Synthesis, Characterization and Evaluation as Aldose Reductase Inhibitors. Vol. 7, No. 5, 2019, pp. 90-97.

doi: $10.11648 /$ j.sjc.20190705.11

Received: September 14, 2019; Accepted: October 15, 2019; Published: October 24, 2019

\begin{abstract}
Role of aldose reductase (ALR2) in diabetic complications such as retinopathy, nephropathy, neuropathy, and cataract etc. is well-evident. ALR2 in the first step of polyol pathway reduces glucose to sorbitol whose elevated level leads to diabetic cataract, characterize by clouding of the lens in the eye that affects vision. Inhibition of ALR2 enzyme with small molecules as inhibitor is a rapid approach for diabetic management. In the present study the synthetic route to synthesize desired benzopyrazines and a library of sixteen (16) methyl benzopyrazines were screened against aldose reductase. From the bioactivity results, the 3'-hydroxyphenyl benzopyrazine 61 was found most active $\left(\mathrm{IC}_{50}=1.34 \pm 0.07 \mu \mathrm{M}\right)$ while 3 'bromophenyl analogue $6 \mathrm{i}$ showed comparable activity for ALR2 $\left(\mathrm{IC}_{50}=3.48 \pm 0.66 \mu \mathrm{M}\right)$ as compared to standard sorbinil $\left(\mathrm{IC}_{50}=3.14 \pm 0.02 \mu \mathrm{M}\right)$. Both compounds (61 and 6i) showed excellent selectivity for ALR2 over aldehyde reductase (ALR1) which has important role in detoxification of toxic aldehydes. The structure of two regio-isomers were fully characterize by ${ }^{1} \mathrm{H}$ and ${ }^{13} \mathrm{C}$ NMR two dimensional NMR techniques including COSY, NOESY, HSQC, and HMBC. Regio-isomers separation was proved to be difficult in different solvent systems. Only an isomer of 3'-bromo benzopyrazine 6i' was isolated that help to assign the structure of regioisomers from NMR data. All the benzopyrazines were fully characterized by using different spectral techniques including ${ }^{1} \mathrm{H},{ }^{13} \mathrm{C} \mathrm{NMR}$, IR spectroscopy, and mass spectrometry.
\end{abstract}

Keywords: Aldose Reductase, Polyol Pathway, Aldehyde Reductase, Benzopyrazines, Diabetic Complications

\section{Introduction}

Diabetes mellitus (DM) is chronic lifetime condition which disrupts body's ability to use glucose from food as energy source. DM is characterized by postprandial increased level of blood glucose which is termed as hyperglycemia [1]. The diabetic complications associated with hyperglycemia are blindness, renal failure, neuropathy, and cardiac arrest etc. Usually, under normal conditions glucose metabolize via glycolytic pathway [2]. However, during hyperglycemia normal pathway of glucose metabolism gets saturated and substantial amount of glucose enters into the polyol pathway. Aldose reductase (ALR2, EC 1.1.1.21) reduces the glucose to sorbitol which further oxidized to fructose with sorbitol dehydrogenase. ALR2 is a cytosolic enzyme that belongs to the class of aldo-keto reductase (AKR) superfamily. It is the first rate limiting enzyme of polyol pathway which reduce glucose to sorbitol. Intracellular sorbitol cannot pass through the cell membrane, hence accumulates within the cell causing osmotic stress that results in diabetic cataract complication [3]. Therefore, inhibition of ALR2 is considered an intelligent approach to reduce the progression of long term 
diabetic complications. Aldehyde reductase (ALR1, 1.1.1.2) is another member of AKR superfamily and share more than $65 \%$ amino acids sequence and structural homology with ALR2. [4] ALR1is present in all tissues and shows substrate specificity towards toxic aldehydes, such as hydroxynonenal, 3-deoxyglucosone, and methylglyoxal, produced in different pathological conditions associated with oxidative stress as in hyperglycemia [5].

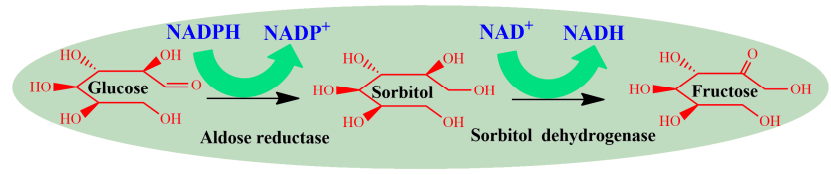

Figure 1. Polyol pathway.

In past years, a range of different molecules has been employed as ALR2 inhibitors [6-10]. Mostly known compounds are carboxylic acids such as tolrestat [11] or cyclic amides like sorbini [12], minalrestat [13] etc. A carboxylic acid drug, named epalrestat [14], is currently available in market for the treatment of neuropathy. However, some limitations like low in vivo efficacy of carboxylic acid drugs, cytotoxicity and harmful side effects of cyclic amides demands new molecules as ARL2 inhibitors. Recently, [15] group reported quinoxalinone derivatives as ALR2 inhibitors (Figure 2). Literature revealed the diverse bioactivities of quinoxaline or benzopyrazine based compounds such as antimycobacterial [16], antileishmanial, [17], anticancer [18], antimalarial activities, [19] cholinesterases, [20-21] and $\alpha$ glycosidase inhibitors [22] etc. Thus, in this study, we synthesized sixteen benzopyrazine derivatives and screen evaluated them against ARL2 as well as ALR1 for selectivity purpose.
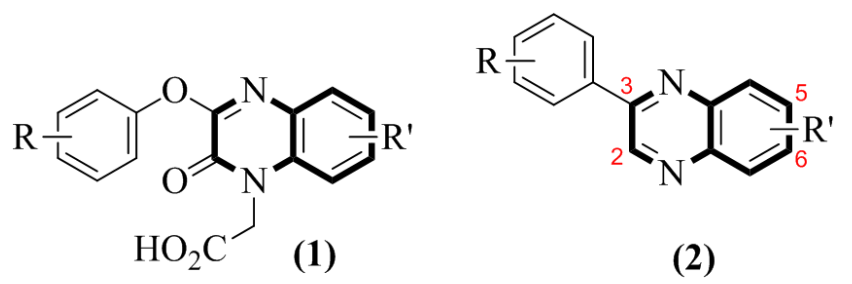

$\mathrm{R} / \mathrm{R}^{\prime}=$ Subsitutents

Figure 2. Nitro-quinoxalinone 1 and benzopyrazine 2 based derivatives.

\subsection{Material and Methods}

All the starting materials including acetophenone derivatives, 4-methylbenzene-1,2-diamine, selenium dioxide were purchased from Sigma-Aldrich and were used without purification unless otherwise stated. HPLC grade dioxane and distill water were used as solvents. Silica gel 60 aluminium-backed plates having $0.063-0.200 \mathrm{~mm}$ as the stationary phase were used for thin layer chromatography (TLC) and flash silica was used for column chromatography. Analytical grade solvents include diethyl ether, ethyl acetate (EtOAc), hexane, and pentane were used as eluents. For TLC spot visualization, UV light $(254 \mathrm{~nm})$ or basic potassium permanganate or vanillin solution were used. $\mathrm{KBr}$ discs were used for IR spectra recording on a Bruker Vector-22 spectrometer. NMR spectra were recorded on Avance Bruker AM spectrometers 300,400 or $500 \mathrm{MHz}$ in the appropriate deuterated solvent at $25^{\circ} \mathrm{C}$. All the chemical shifts were recorded on the $\delta$-scale (ppm) using residual solvents as an internal standard (DMSO; ${ }^{1} \mathrm{H} 2.50,{ }^{13} \mathrm{C} 39.43$ and $\mathrm{CHCl}_{3} ;{ }^{1} \mathrm{H}$ 7.26, $\left.{ }^{13} \mathrm{C} 77.16\right)$. Mass spectra $\left(\mathrm{ESI}^{+}\right)$were recorded at Finnigan-MAT-321A, Germany by using electrospray (ES+), electron impact (EI+ EI+) or FAB (Fast atom bombardment) techniques.

\subsection{General Procedure for the Synthesis of 6/7-methyl-2-arylbenzopyrazines 6(a-o)}

In a typical experiment, an oven dried round-bottomed flask was charged with acetophenone $(240 \mathrm{mg}, 2 \mathrm{mmol})$, dioxane/water (10:1) and selenium dioxide (222 $\mathrm{mg}, 2 \mathrm{mmol})$ at room temperature. The resulting solution was stirred at $100^{\circ} \mathrm{C}$ for 3-4 h until no starting material was left over TLC plate. The reaction mixture was cold to room temperature and filtered. Filtrate was concentrated on a rotary evaporator under reduced pressure. Water $(30 \mathrm{~mL})$ was added and stirred at $100^{\circ} \mathrm{C}$ and then treated with activated charcoal. The corresponding dicarbonyl compound 4 was collected as white solid and used without purification in the next reaction. [23]. Compound 4 was treated with 4-methylbenzene-1,2-diamine 5 (146 mg, $1.2 \mathrm{mmol}$ ) at room temperature for $0.5-1 \mathrm{~h}$ until the complete consumption of dicarbonyl compound 4 as monitored by TLC analysis. The reaction mixture was diluted with water $(40 \mathrm{~mL})$ water and extracted with ethyl acetate $(25 \mathrm{~mL} \times 3)$. The combined organic layers were dried over anhydrous $\mathrm{MgSO}_{4}$, filtered and evaporated on rotary evaporator. The crude material was purified by silica gel column chromatography (EtOAc / Hexane 1:3 to 1:1). The benzopyrazines $6(\mathrm{a}-\mathrm{o})$ were obtained in variable yields. [24]

\subsection{Spectral Data}

6/7-Methyl-2-phenylbenzopyrazine (6a) Yield 75\%, IR $\left(v_{\max }, \mathrm{cm}^{-1}\right)$ : (Solid, KBr) 3853, 3726, 3628, 1701, 1539, 1452, 1307, 1026, 796, 680. ${ }^{1} \mathrm{H}$ NMR (500 MHz, DMSO, 1/0.5 mixture of isomers): н $^{9.52 / 9.50}(1 \mathrm{H}$, each s, $\mathrm{CH})$, 8.33-8.30 (2H, m, ArH), 8.03/8.01 (1H, each d, $J=8.5 \mathrm{~Hz}$, $\operatorname{Ar} H), 7.93 / 7.90(1 \mathrm{H}$, each s, $\operatorname{Ar} H), 7.71 / 7.68(1 \mathrm{H}$, each dd, $J$ $=1.5,8.5 \mathrm{~Hz}, \operatorname{Ar} H), 7.62-7.53(3 \mathrm{H}, \mathrm{m}, \operatorname{Ar} H), 2.58(3 \mathrm{H}, \mathrm{s}$, $\left.\mathrm{CH}_{3}\right) ;{ }^{13} \mathrm{C} \mathrm{NMR}\left(75 \mathrm{MHz}, \mathrm{CDCl}_{3}\right)$ : ${ }_{\text {c }} 150.8 / 150.1$ (C), $143.4 / 142.6 \quad(\mathrm{CH}), \quad 141.4 / 141.1 \quad(\mathrm{C}), 140.7 / 139.5 \quad(\mathrm{C})$, $139.9 / 139.8$ (C), 136.13/136.12 (C), 132.6/131.9 (CH), 130.3/130.1 (CH), $129(\mathrm{CH} \times 2), 128.7 / 128.3(\mathrm{CH})$, $127.9 / 127.5(\mathrm{CH}), 127.3 / 127.2(\mathrm{CH}), 21.21 / 21.18\left(\mathrm{CH}_{3}\right)$. MS-EI $m / z(\%), 220\left(\mathrm{M}^{+}, 100\right)$.

6/7-Methyl-2-(2'-methylphenyl)benzopyrazine (6b) Yield 33\%, (Solid, KBr) 3855, 3736, 3689, 3024, 2968, 1620, 1545, 1492, 1454, 1309, 1037, 827, 767. ${ }^{1} \mathrm{H}$ NMR (400 MHz,

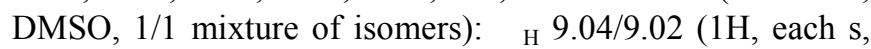
CH), 7.99 (1H, app t, $J=9.0 \mathrm{~Hz}, \mathrm{Ar} H), 7.90 / 7.88(1 \mathrm{H}$, each brs, $\operatorname{Ar} H), 7.70-7.66(1 \mathrm{H}, \mathrm{m}, \operatorname{Ar} H), 7.57(1 \mathrm{H}, \mathrm{d}, J=7.6 \mathrm{Ar} H)$, 
7.40-7.35 (3H, m, $\mathrm{Ar} H), 2.56 / 2.55\left(3 \mathrm{H}\right.$, each s, $\left.\mathrm{CH}_{3}\right), 2.40$ $\left(3 \mathrm{H}, \mathrm{s}, \mathrm{CH}_{3}\right) ;{ }^{13} \mathrm{C} \mathrm{NMR}\left(100 \mathrm{MHz}, \mathrm{CDCl}_{3}\right):{ }_{\mathrm{C}} 154.2 / 153.5$ (C), 145.8/145 (CH), 141.2/140.5 (C), 140.6/140.1 (C), 139.6/138.9 (C), 136.8 (C), 136.3/136.2 (C), 132.5/132 (CH), 130.93/130.90 (CH), $129.9(\mathrm{CH} \times 2), 129.15 / 129.11(\mathrm{CH})$, 128.6/128.4 (CH), 127.8/127.6 (CH), $126.1(\mathrm{CH}), 21.2$ $\left(\mathrm{CH}_{3}\right), 19.9\left(\mathrm{CH}_{3}\right)$. MS-EI $m / z(\%), 234\left(\mathrm{M}^{+}, 63\right), 233.2$ (100). HRMS $\mathrm{C}_{16} \mathrm{H}_{14} \mathrm{~N}_{2}$ calculated 234.1157, found 234.1140 .

6/7-Methyl-2-(3'-methylphenyl)benzopyrazine (6c) Yield $89 \%$, IR ( $\left.v_{\max }, \mathrm{cm}^{-1}\right)$ : (Solid, KBr) 3423, 3043, 2918, 2854, $1612,1539,1440,1313,1193,1132,1047,1014,966 .{ }^{1} \mathrm{H}$ NMR (400 MHz, DMSO, 1/1 mixture of isomers): 9.47/9.44 (1H, each s, CH), $8.11(1 \mathrm{H}$, brs, $\mathrm{ArH}), 8.08(1 \mathrm{H}, \mathrm{d}$, $J=7.6 \mathrm{~Hz}, \operatorname{Ar} H), 8.01 / 7.98(1 \mathrm{H}$, each d, $J=8.8 / 8.4 \mathrm{~Hz}$, $\operatorname{Ar} H), 7.90 / 7.87(1 \mathrm{H}$, each brs, $\operatorname{Ar} H), 7.68 / 7.64(1 \mathrm{H}$, each dd $J=1.2,8.8 \mathrm{~Hz}, \operatorname{Ar} H), 7.45(1 \mathrm{H}$, app td, $J=2,7.6 \mathrm{~Hz}, \operatorname{Ar} H)$, $7.35(1 \mathrm{H}$, app d, $J=6.8 \mathrm{~Hz}, \operatorname{Ar} H), 2.55\left(3 \mathrm{H}, \mathrm{s}, \mathrm{CH}_{3}\right), 2.43$ $\left(3 \mathrm{H}, \mathrm{s}, \mathrm{CH}_{3}\right.$. MS-EI $m / z(\%), 234\left(\mathrm{M}^{+}, 100\right)$. HRMS $\mathrm{C}_{16} \mathrm{H}_{14} \mathrm{~N}_{2}$ calculated 234.1157, found 234.1146.

6/7-Methyl-2-(4'-methylphenyl)benzopyrazine (6d) Yield $26 \%$, IR $\left(v_{\max }, \mathrm{cm}^{-1}\right)$ : (Solid, KBr) 3726, 3625, 2924, 1654, 1541, 1218, 1047, 827, 673. ${ }^{1} \mathrm{H}$ NMR (400 MHz, DMSO, 1/0.5 mixture of isomers): ${ }_{\mathrm{H}} 9.46 / 9.44(1 \mathrm{H}$, each $\mathrm{s}, \mathrm{CH})$, $8.19(2 \mathrm{H}, \mathrm{d}, J=8.4 \mathrm{~Hz}, \operatorname{Ar} H), 7.97(1 \mathrm{H}, \operatorname{app~t}, J=7.8 \mathrm{~Hz}$, $\operatorname{Ar} H), 7.87 / 7.86(1 \mathrm{H}$, each brs, $\operatorname{Ar} H), 7.68 / 7.64(1 \mathrm{H}$, each dd $J=1.2,8.2 \mathrm{~Hz}, \operatorname{Ar} H), 7.38(2 \mathrm{H}, \mathrm{d}, J=8.0 \mathrm{~Hz}, \operatorname{Ar} H), 2.55$ $\left(3 \mathrm{H}, \mathrm{s}, \mathrm{CH}_{3}\right), 2.39\left(3 \mathrm{H}, \mathrm{s}, \mathrm{CH}_{3}\right) ;{ }^{13} \mathrm{C} \mathrm{NMR}(100 \mathrm{MHz}$, $\left.\mathrm{CDCl}_{3}\right):{ }_{\mathrm{C}} 150.9 / 150.2(\mathrm{C}), 143.5 / 142.7(\mathrm{CH}), 141.5 / 141.1$ (C), 140.8/140.3 (C), 140.1 (C), 139.9/139.5 (C), 133.4 (C), $132.7 / 131.9(\mathrm{CH}), 129.8(\mathrm{CH} \times 2), 128.7 / 128.5(\mathrm{CH})$, 127.9/127.6 (CH), 127.3/127.2 (CH x 2), 21.4/21.3 $\left(\mathrm{CH}_{3}\right), 21$ $\left(\mathrm{CH}_{3}\right)$. MS-EI $\mathrm{m} / \mathrm{z}(\%), 234\left(\mathrm{M}^{+}, 100\right)$, HRMS $\mathrm{C}_{16} \mathrm{H}_{14} \mathrm{~N}_{2}$ calculated 234.1157, found 234.0106.

6/7-Methyl-2-(3'-fluorophenyl)benzopyrazine (6e) Yield $21 \%$, IR ( $\left.v_{\max }, \mathrm{cm}^{-1}\right)$ : (Solid, KBr) 3433, 2924, 1625, 1404, 1028, 873. ${ }^{1} \mathrm{H}$ NMR (400 MHz, DMSO, 1/1 mixture of isomers): ${ }_{\mathrm{H}}$ 9.56/9.53 $(1 \mathrm{H}$, each $\mathrm{s}, \mathrm{CH}), 8.19-8.09(1 \mathrm{H}, \mathrm{m}$, $\operatorname{Ar} H), 8.03(1 \mathrm{H}$, app t, $J=8.4 \mathrm{~Hz}, \operatorname{Ar} H), 7.94 / 7.91(1 \mathrm{H}$, each brs, $\operatorname{Ar} H), 7.75-7.68(1 \mathrm{H}, \mathrm{m}, \operatorname{Ar} H), 7.67-7.60(1 \mathrm{H}, \mathrm{m}, \operatorname{Ar} H)$, 7.43-7.37 (1H, m, ArH), $2.58\left(1 \mathrm{H}, \mathrm{s}, \mathrm{CH}_{3}\right) ;{ }^{13} \mathrm{C}$ NMR $(100$ $\left.\mathrm{MHz}, \mathrm{CDCl}_{3}\right)$ : с $164.3 / 161.1$ (C), 143.5/142.7 (CH),

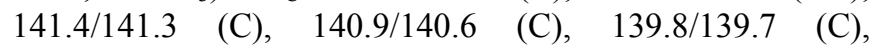
138.7/138.6 (C), $137.9(\mathrm{C}), 132.9 / 132.4(\mathrm{CH}), 131.2 / 131.1$ $(\mathrm{CH}), \quad 129.2 / 129.2(\mathrm{CH}), 128.8 / 128.4(\mathrm{CH}), \quad 127.8 / 127.6$ $(\mathrm{CH}), \quad 123.46 / 123.42 / 123.35 / 123.32 \quad(\mathrm{CH})$, 117.2/117.1/116.9/116.8 (CH), 114.01/113.95/113.74/113.65 (CH). MS-EI $m / z(\%), 238.1\left(\mathrm{M}^{+}, 100\right)$, HRMS $\mathrm{C}_{15} \mathrm{H}_{11} \mathrm{~N}_{2} \mathrm{~F}_{1}$ calculated 238.0985, found 238.0924.

6/7-Methyl-2-(2'-chlorophenyl)benzopyrazine (6f) Yield $48 \%$, IR $\left(v_{\max }, \mathrm{cm}^{-1}\right)$ : (Solid, KBr) 3427, 3045, 2918, 1620, 1539, 1479, 1436, 1367, 1313, 1130, 1076, 1035, 962, 924. ${ }^{1} \mathrm{H}$ NMR (400 MHz, DMSO, 1/0.8 mixture of isomers): ${ }_{\mathrm{H}}$ 9.14/9.11 (1H, each s, CH), $8.03(2 \mathrm{H}, \mathrm{dd}, J=4.0,8.4 \mathrm{~Hz}$, $\operatorname{Ar} H), 7.93 / 7.92(1 \mathrm{H}$, each brs, $\operatorname{Ar} H), 7.73(1 \mathrm{H}, \mathrm{d}, J=7.6 \mathrm{~Hz}$, $\operatorname{Ar} H), 7.66(2 \mathrm{H}$, app d, $J=7.6 \mathrm{~Hz}, \operatorname{Ar} H), 7.58-7.52(1 \mathrm{H}, \mathrm{m}$, $\mathrm{ArH}), 2.58 / 2.57\left(3 \mathrm{H}, \mathrm{s}, \mathrm{CH}_{3}\right) .{ }^{13} \mathrm{C} \mathrm{NMR}(100 \mathrm{MHz}, \mathrm{DMSO})$ :
C $151.9 / 151.2(\mathrm{C}), 145.9 / 145.2(\mathrm{CH}), 141.5 / 140.9(\mathrm{C})$, $140.1 / 140.8 \quad$ (C), $139.9 / 139.3 \quad$ (C), 136.21/136.18 (C), 132.9/132.8 (CH), $132.1(\mathrm{CH}), 131.56 / 131.27(\mathrm{CH}), 131.2$ (CH), $130(\mathrm{CH})$, 128.8/128.5 (CH), 127.9/127.6 (CH), 127.8 (CH), $21.3\left(\mathrm{CH}_{3}\right)$; MS-EI m/z (\%), $254\left(\mathrm{M}^{+}, 98\right), 219$ (100). HRMS $\mathrm{C}_{15} \mathrm{H}_{11} \mathrm{~N}_{2} \mathrm{Cl}_{1}$ calculated 254.0611, found 254.0619.

6/7-Methyl-2-(3'-chlorophenyl)benzopyrazine (6g) Yield $33 \%,{ }^{1} \mathrm{H}$ NMR (400 MHz, DMSO, $1 / 0.8$ mixture of isomers): н 9.52/9.50 (1H, each s, CH), $8.33(1 \mathrm{H}$, brs, $\mathrm{Ar} H), 8.27-$ $8.25(1 \mathrm{H}, \mathrm{m}, \mathrm{Ar} H), 8.02 / 7.99(1 \mathrm{H}$, each d, $J=8.4 \mathrm{~Hz}, \operatorname{Ar} H)$, 7.92/7.89 $(1 \mathrm{H}$, each brs, $\operatorname{Ar} H), 7.70(1 \mathrm{H}$, app t, $J=9.8 \mathrm{~Hz}$, $\mathrm{ArH}), 7.61-7.59(2 \mathrm{H}, \mathrm{m}, \mathrm{ArH}), 2.56\left(3 \mathrm{H}, \mathrm{s}, \mathrm{CH}_{3}\right) .{ }^{13} \mathrm{C} \mathrm{NMR}$ (125 MHz, DMSO): c 149.2/148.7 (C), 143.6/142.8 (CH), 141.44/141.39 (C), 141.1/140.7 (C), 139.9/139.8 (C), 138.3 (C), 134.1 (C), 133/132.6 (CH), 131.1 (CH), 130.2/130 (CH), $128.9 / 128.5(\mathrm{CH}), 128.1 / 127.7(\mathrm{CH}), 127 / 126.9(\mathrm{CH})$, 126.1/125.9 (CH), $21.4\left(\mathrm{CH}_{3}\right)$; MS-EI $m / z(\%), 254\left(\mathrm{M}^{+}, 98\right)$, 219 (81). HRMS $\mathrm{C}_{15} \mathrm{H}_{11} \mathrm{~N}_{2} \mathrm{Cl}_{1}$ calculated 254.0611, found 254.0619 .

6/7-Methyl-2-(2'-bromophenyl)benzopyrazine (6h) Yield 48\%, (Solid, KBr) 3789, 3730, 2920, 2851, 1024, 772, 648. ${ }^{1} \mathrm{H}$ NMR (400 MHz, DMSO, 1/1 mixture of isomers): $\mathrm{H}_{\mathrm{H}}$ 9.11/9.08 $(1 \mathrm{H}$, each s, CH), 8.05/8.04 $(1 \mathrm{H}$, each $\mathrm{d}, J=8.4$ $\mathrm{Hz}, \operatorname{Ar} H), 7.94 / 7.92(1 \mathrm{H}$, each brs, $\mathrm{Ar} H), 7.83(1 \mathrm{H}, \mathrm{d} J=8$ $\mathrm{Hz}, \operatorname{Ar} H), 7.75(1 \mathrm{H}, \mathrm{d}, J=8.8 \mathrm{~Hz}, \operatorname{Ar} H), 7.69(1 \mathrm{H}, \mathrm{d}, J=7.6$ $\mathrm{Hz}, \operatorname{Ar} H), 7.58(1 \mathrm{H}, \mathrm{t}, J=7.6 \mathrm{~Hz}, \operatorname{Ar} H), 7.48(1 \mathrm{H}, \mathrm{t}, J=7.6$ $\mathrm{Hz}, \mathrm{ArH}), 2.60 / 2.59\left(3 \mathrm{H}\right.$, each s, $\left.\mathrm{CH}_{3}\right) .{ }^{13} \mathrm{C} \mathrm{NMR}(125 \mathrm{MHz}$, DMSO): $\quad$ с $145.8(\mathrm{C}), 145.1(\mathrm{CH}), 140.9(\mathrm{C}), 140.86(\mathrm{C})$, $138.4(\mathrm{C}), 138.1$ (C), 133 (C), 132.8/132.7 (C), $131.9(\mathrm{CH})$, $131.2(\mathrm{CH}), 128.7 / 128.4(\mathrm{CH}), 128.1(\mathrm{CH}), 127.8 / 127.6$ (CH), $121.4(\mathrm{CH}), 21.3\left(\mathrm{CH}_{3}\right)$; MS-EI $m / z(\%), 298\left(\mathrm{M}^{+}, 20\right)$, 299 (21), 219 (100), HRMS $\mathrm{C}_{15} \mathrm{H}_{11} \mathrm{~N}_{2} \mathrm{Br}$ calculated 298.0106, found 298.0107 .

6/7-Methyl-2-(3'-bromophenyl)benzopyrazine (6i) Yield 62\%, (Solid, KBr) 3853, 3696, 1618, 1537, 1434, 1307, 1202, 1049, 962, 773, 694. ${ }^{1} \mathrm{H}$ NMR (500 MHz, DMSO, 1/0.6 mixture of isomers): ${ }_{\mathrm{H}} 9.55 / 9.53(1 \mathrm{H}$, each $\mathrm{s}, \mathrm{CH})$, $8.50(1 \mathrm{H}$, app q, $J=2.0 \mathrm{~Hz}, \operatorname{Ar} H), 8.33(1 \mathrm{H}, \mathrm{d}, J=7.5 \mathrm{~Hz}$, $\operatorname{Ar} H), 8.05 / 8.01(1 \mathrm{H}$, each d, $J=8.5 \mathrm{~Hz}, \mathrm{Ar} H), 7.95 / 7.91$ $(1 \mathrm{H}$, each brs, $\operatorname{Ar} H), 7.77-7.70(2 \mathrm{H}, \mathrm{m}, \mathrm{Ar} H), 7.55$ (1H, td, $J$ $=3,8 \mathrm{~Hz}, \mathrm{Ar} H), 2.58\left(3 \mathrm{H}, \mathrm{s}, \mathrm{CH}_{3}\right) ;{ }^{13} \mathrm{C} \mathrm{NMR}(100 \mathrm{MHz}$,

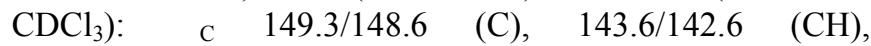
141.43/141.39 (C), 141.1/140.7 (C), 139.89/139.77 (C), $138.5(\mathrm{C}), 133.04 / 132.93(\mathrm{CH}), 132.6(\mathrm{CH}), 131.3(\mathrm{CH})$, 129.9/129.8 (CH), 128.9/128.5 (CH), 128.1/127.7 (CH), 126.4/126.3 (CH), $122.6(\mathrm{C}), 21.4\left(\mathrm{CH}_{3}\right)$. Data for single isomer $\left(6 \mathrm{i}^{\prime}\right),{ }^{1} \mathrm{H}$ NMR (300 MHz, DMSO): $\mathrm{CH}), 8.48$ (1H, brs, $\mathrm{ArH}), 8.32(1 \mathrm{H}, \mathrm{d}, J=9 \mathrm{~Hz}, \mathrm{Ar} H), 8.01$ $(1 \mathrm{H}, \mathrm{d}, J=6 \mathrm{~Hz}, \operatorname{Ar} H), 7.93(1 \mathrm{H}, \mathrm{s}, \operatorname{Ar} H), 7.75(1 \mathrm{H}, \mathrm{d}, J=9$ $\mathrm{Hz}, \operatorname{Ar} H), 7.68(1 \mathrm{H}, \mathrm{dd}, J=3,9 \mathrm{~Hz}, \operatorname{Ar} H), 7.54(1 \mathrm{H}, \mathrm{t}, J=9$ $\mathrm{Hz}, \mathrm{ArH}), 2.57$ (3H, s, $\left.\mathrm{CH}_{3}\right)$. MS-EI $m / z(\%), 298\left(\mathrm{M}^{+}, 100\right)$, 299 (57), 219 (90), HRMS $\mathrm{C}_{15} \mathrm{H}_{11} \mathrm{~N}_{2} \mathrm{Br}$ calculated 298.0106, found 298.0106 .

6/7-Methyl-2-(4'-bromophenyl)benzopyrazine (6j) Yield $33 \%$, (Solid, KBr) 3695, 1589, 1313, 1218, 1006, 829. ${ }^{1} \mathrm{H}$ NMR (400 MHz, DMSO, 1/1 mixture of isomers): $\mathrm{H}$ 9.52/9.50 (1H, each s, CH), $8.28(2 \mathrm{H}, \mathrm{d}, J=8 \mathrm{~Hz}, \mathrm{Ar} H), 8.01$ 
$(1 \mathrm{H}$, app t $, J=8.8 \mathrm{~Hz}, \operatorname{Ar} H), 7.92 / 7.90(1 \mathrm{H}$, each brs, $\mathrm{Ar} H)$, $7.80(2 \mathrm{H}, \mathrm{dd}, J=2.4,8.4 \mathrm{~Hz}, \operatorname{Ar} H), 7.72 / 7.69(1 \mathrm{H}$, each d, $J$ $=8.8 \mathrm{~Hz}, \mathrm{Ar} H), 2.58\left(3 \mathrm{H}, \mathrm{s}, \mathrm{CH}_{3}\right) ;{ }^{13} \mathrm{C} \mathrm{NMR}(125 \mathrm{MHz}$, DMSO): $\quad$ c $149.8 / 149.1(\mathrm{C}), 143.4 / 142.6(\mathrm{CH}), 141.4 / 141.3$ (C), 141 (C), 140.5 (C), 139.78/139.71 (C), 135.4 (C), 133/132.4 (CH), 132.1 (CH x 2), 129.4/129.3 ( $\mathrm{CH} \times 2)$, 128.8/128.5 (CH), 127.9/127.6 (CH), 124,2/124.1 (CH), 21.3 $\left(\mathrm{CH}_{3}\right)$. MS-EI $\mathrm{m} / \mathrm{z}(\%), 298\left(\mathrm{M}^{+}, 100\right), 299$ (98). HRMS $\mathrm{C}_{15} \mathrm{H}_{11} \mathrm{~N}_{2} \mathrm{Br}$ calculated 298.0106, found 298.0111.

6/7-Methyl-2-(4'-iodophenyl)benzopyrazine (6k) Yield 72\%, (Solid, KBr) 3855, 3691, 3627, 1701, 1541, 1219, 827, 773, 671. ${ }^{1} \mathrm{H}$ NMR (400 MHz, DMSO, 1/0.8 mixture of isomers): ${ }_{\mathrm{H}}$ 9.49/9.46 $(1 \mathrm{H}$, each s, $\mathrm{CH}), 8.08(2 \mathrm{H}, \mathrm{d}, J=8.4$ $\mathrm{Hz}, \operatorname{Ar} H), 8.01 / 7.96(1 \mathrm{H}$, each d, $J=7.2 \mathrm{~Hz}, \operatorname{Ar} H), 7.96(2 \mathrm{H}$, $\mathrm{d}, J=8.8 \mathrm{~Hz}, \operatorname{Ar} H), 7.89 / 7.88(1 \mathrm{H}$, each brs, $\operatorname{Ar} H), 7.66(1 \mathrm{H}$, app t, $J=10.2 \mathrm{~Hz}, \mathrm{Ar} H), 2.56\left(3 \mathrm{H}, \mathrm{s}, \mathrm{CH}_{3}\right) ;{ }^{13} \mathrm{C} \mathrm{NMR}(75$ $\mathrm{MHz}, \mathrm{DMSO}): \quad$ c $149.9 / 149.3$ (C), 143.2/142.4 (CH), 141.4/141.2 (C), 140.9/139.4 (C), 139.7/139.9 (C), 137.9 (CH x 2), 135.6 (C), 132.9/132.2 (CH), 129.2/129.1 (CH x 2), 128.7/128 (CH), 127.8/127.9 (CH), 97.8/97.6 (C), 21.2 $\left(\mathrm{CH}_{3}\right)$. MS-EI $\mathrm{m} / \mathrm{z}(\%), 298\left(\mathrm{M}^{+}, 100\right), 299$ (98). HRMS $\mathrm{C}_{15} \mathrm{H}_{11} \mathrm{~N}_{2} \mathrm{I}$ calculated 345.9967, found 345.9958.

6/7-Methyl-2-(4'-hydroxyphenyl)benzopyrazine (61) Yield $35 \%,{ }^{1} \mathrm{H}$ NMR (400 MHz, DMSO, 1/1 mixture of isomers): н 10.02/10 (1H, brs, OH), 9.41/9.38 $(1 \mathrm{H}$, each s, $\mathrm{CH}), 8.16$ $(2 \mathrm{H}, \mathrm{dd}, J=3.2,8.4 \mathrm{~Hz}, \mathrm{Ar} H), 7.92(1 \mathrm{H}$, app dd, $J=2,8.8$ $\mathrm{Hz}, \operatorname{Ar} H), 7.82(1 \mathrm{H}$, brs, $\operatorname{Ar} H), 7.63 / 7.57(1 \mathrm{H}$, each d, $J=8.4$ $\mathrm{Hs}, \operatorname{Ar} H), 6.94(2 \mathrm{H}, \mathrm{dd}, J=1.6,8.4 \mathrm{~Hz}, \operatorname{Ar} H), 2.53(3 \mathrm{H}, \mathrm{s}$, $\left.\mathrm{CH}_{3}\right) .{ }^{13} \mathrm{C}$ NMR (75 MHz, DMSO): c $^{159.7 / 159.6}(\mathrm{C})$, 150.8/150.2 (C), 143.1/142.3 (CH), 141.5/141.5 (C), 140.4

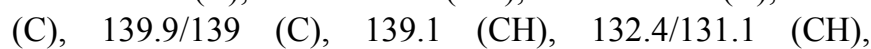
$128.9 / 128.8(\mathrm{CH} \times 2), 128.4 / 128.3(\mathrm{CH}), 127.6 / 127.5(\mathrm{C})$, 126.99 (C), 115.9 (CH x 2), 21.2/21.1 $\left(\mathrm{CH}_{3}\right)$. MS-EI $\mathrm{m} / \mathrm{z}$ (\%), $236\left(\mathrm{M}^{+}, 100\right)$.

6/7-Methyl-2-(2'-nitrophenyl)benzopyrazine (6m) Yield $34 \%$, IR ( $\left.v_{\max }, \mathrm{cm}^{-1}\right)$ : (Solid, KBr) 3429, 2922, 2852, 1616, $1520,1488,1436,1336,1132,1035,964 .{ }^{1} \mathrm{H}$ NMR (400 $\mathrm{MHz}, \mathrm{DMSO}, 1 / 0.8$ mixture of isomers): н $9.19 / 9.17(1 \mathrm{H}$, each s, CH), $8.14(1 \mathrm{H}, \mathrm{d}, J=10.4 \mathrm{~Hz}, \mathrm{Ar} H), 8.06-7.87(4 \mathrm{H}$, $\mathrm{m}, \operatorname{Ar} H), 7.82-7.71(2 \mathrm{H}, \mathrm{m}, \mathrm{Ar} H), 2.57 / 2.56\left(3 \mathrm{H}, \mathrm{s}, \mathrm{CH}_{3}\right)$. MS-EI $m / z \quad(\%), 265.1 \quad\left(\mathrm{M}^{+}, 100\right)$. HRMS $\mathrm{C}_{15} \mathrm{H}_{11} \mathrm{O}_{2} \mathrm{~N}_{3}$ calculated 265.0851 , found 265.0836 .

6/7-Methyl-2-(3'-nitrophenyl)benzopyrazine (6n) Yield $92 \%$, IR $\left(v_{\max }, \mathrm{cm}^{-1}\right)$ : (Solid, KBr) 3429, 2922, 1620, 1531, 1440, 1348, 1097, 1058, 966. ${ }^{1} \mathrm{H}$ NMR (400 MHz, DMSO, 1/1 mixture of isomers): ${ }_{\mathrm{H}} 9.64 / 9.62(1 \mathrm{H}$, each $\mathrm{s}, \mathrm{CH}), 9.08$ $(1 \mathrm{H}, \mathrm{brs}, \operatorname{Ar} H), 8.76(1 \mathrm{H}, \mathrm{d}, J=7.6 \mathrm{~Hz}, \mathrm{Ar} H), 8.38(1 \mathrm{H}, \mathrm{d}, J$ $=8 \mathrm{~Hz}, \operatorname{Ar} H), 8.09 / 8.04(1 \mathrm{H}$, each $\mathrm{d}, J=8.8 \mathrm{~Hz}, \operatorname{Ar} H)$, 7.99/7.94 $(1 \mathrm{H}$, each brs, $\operatorname{Ar} H), 7.88(1 \mathrm{H}, \mathrm{td}, J=1.2,7.6 \mathrm{~Hz}$, $\mathrm{ArH}), 7.74(1 \mathrm{H}$, app t, $J=9.2 \mathrm{~Hz}, \mathrm{ArH}), 2.59\left(3 \mathrm{H}, \mathrm{s}, \mathrm{CH}_{3}\right)$; ${ }^{13} \mathrm{C}$ NMR $\left(75 \mathrm{MHz}, \mathrm{CDCl}_{3}\right):$ c 148.67 (C), 148.5/147.96 (C), $143.62 / 142.8 \quad(\mathrm{CH}), \quad 141.6 / 140.1 \quad(\mathrm{C}), 141.3 \quad(\mathrm{C})$,

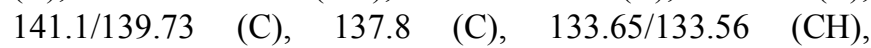
$\begin{array}{llllll}133.2 / 132.9 & (\mathrm{CH}), & 130.8 & (\mathrm{CH}), & 128.9 / 128.1 & (\mathrm{CH}),\end{array}$ 128.5/127.7 (CH), 124.8/124.7 (CH), 121.8/121.7 (CH), 21.4 $\left(\mathrm{CH}_{3}\right)$. MS-EI $\mathrm{m} / z(\%), 265\left(\mathrm{M}^{+}, 46\right), 219$ (75), 89 (100). HRMS $\mathrm{C}_{15} \mathrm{H}_{11} \mathrm{O}_{2} \mathrm{~N}_{3}$ calculated 265.0851, found 265.0842.
6/7-Methyl-2-(4'-piperidinylphenyl)benzopyrazine (6o) Yield $88 \%,{ }^{1} \mathrm{H}$ NMR (400 MHz, DMSO, 1/1 mixture of isomers): н $9.41 / 9.38(1 \mathrm{H}$, each s, CH), $8.16(2 \mathrm{H}, \mathrm{dd}, J=$ $3.2,8.8 \mathrm{~Hz}, \operatorname{Ar} H), 7.92(1 \mathrm{H}, \mathrm{dd}, J=2.4,8.4 \mathrm{~Hz}, \mathrm{Ar} H), 7.82$ (1H, brs, $\operatorname{Ar} H), 7.63 / 7.57$ (1H, each dd, $J=1.2,8.4 \mathrm{Hs}, \operatorname{Ar} H)$, $7.05(2 \mathrm{H}, \mathrm{dd}, J=8 \mathrm{~Hz}, \mathrm{Ar} H), 3.32\left(4 \mathrm{H}\right.$, obscured by $\mathrm{H}_{2} \mathrm{O}$ signals), $2.53\left(3 \mathrm{H}, \mathrm{s}, \mathrm{CH}_{3}\right), 1.59\left(6 \mathrm{H}\right.$, brs, $\left.\left(\mathrm{CH}_{2}\right)_{3}\right)$; MS-EI $m / z(\%), 303\left(\mathrm{M}^{+}, 100\right)$; HRMS $\mathrm{C}_{20} \mathrm{H}_{21} \mathrm{~N}_{3}$ calculate 303.1735, found 303.1738 .

\subsection{Bioassay Protocol}

\subsubsection{Isolation and Purification of Aldehyde (ALR1) and Aldose (ALR2) Reductase}

Following the previously described procedure [25], aldose reductase (ALR2) extraction and purification; from the local slaughter house calf eyes were removed from a freshly slaughtered animal. Sample was kept frozen until used. Lenses were carefully removed from calf eyes. 100$200 \mathrm{~g}$ of lenses was homogenized in cold distilled water. Homogenate was centrifuged at $10,000 \mathrm{rpm}$ at $0-4^{\circ} \mathrm{C}$ for 20 min to remove insoluble material. The supernatant was precipitated with $40 \%$ saturated ammonium sulfate, followed by $50 \%$ and $75 \%$ salt saturation. The pellet from the last step, possessing pure ALR2 activity, was dissolved in $0.05 \mathrm{M} \mathrm{NaCl}$ and dialyzed against $4 \mathrm{~L}$ of $0.05 \mathrm{M} \mathrm{NaCl}$ overnight and stored in small aliquots in liquid nitrogen container. [26]

Aldehyde reductase (ALR1) isolation and purification; from local slaughter house calf kidneys were obtained which were then dissolved in 3 volumes of $10 \mathrm{mM}$ sodium phosphate buffer having $\mathrm{pH} 7.2$, containing EDTA dipotassium salt $(2 \mathrm{mM})$, sucrose $(0.25 \mathrm{M})$ and $\beta$ mercaptoethanol $(2.5 \mathrm{mM})$. A knife homogenizer was used to homogenize the solution. The homogenate centrifuged at $12,000 \mathrm{rpm}$ at $4{ }^{\circ} \mathrm{C}$ for $45 \mathrm{~min}$ to remove insoluble materials. The supernatant was collected and precipitated with $40 \%, 50 \%$ and finally $75 \%$ powdered ammonium sulfate saturation. The precipitate collected after saturation with $75 \%$ ammonium sulfate was re-dissolved in potassium phosphate buffer and dialyzed against the same buffer overnight and stored in liquid nitrogen container until used [27].

\subsubsection{In-vitro Assay of Aldose and Aldehyde Reductase Inhibition}

Following the procedure previously described, [28] the activity of aldose reductase (ALR2) was determine by observing the change in the absorbance at $340 \mathrm{~nm}$. Sorbinil [29] and valproic acid [30] were used as positive control for ALR2 and ALR1, respectively The reaction mixture contained $100 \mathrm{mM}$ potassium phosphate buffer ( $\mathrm{pH}$ 6.2), 20 $\mu \mathrm{L}$ of the inhibitor, $0.1 \mathrm{mM}$ NADPH and enzyme preparation in a total volume of $300 \mu \mathrm{L}$. The resulting mixture was incubated for $10 \mathrm{~min}$ at $37^{\circ} \mathrm{C}$. The reaction was initiated by the addition of $90 \mu \mathrm{L}$ of $10 \mathrm{mM}$ sodium DL-glyceraldehyde as a substrate. To correct the oxidation of NADPH, reference was used which contained all the above mentioned reagents 
except substrate [31].

The activity of ALR1 for synthetic compound was determined by monitoring the change in UV absorption by $\mathrm{NADPH}$ at $340 \mathrm{~nm}$. The reaction mixture contained $100 \mu \mathrm{M}$ potassium phosphate buffer ( $\mathrm{pH} 6.2$ ), $20 \mu \mathrm{L}$ of the inhibitor, $0.1 \mathrm{mM}$ NADPH and enzyme preparation in a total volume of $300 \mu \mathrm{L}$. The resulting mixture was incubated for $10 \mathrm{~min}$ at $37^{\circ} \mathrm{C}$. The reaction was initiated by the addition of $90 \mu \mathrm{L}$ of $10 \mathrm{mM}$ sodium D-glucoronate as a substrate. One unit of enzyme was defined as the amount of enzyme required to catalyze the oxidation of $1.0 \mathrm{mM}$ NADPH under the above mentioned conditions. Appropriate blanks were used for corrections. [32]

\section{Results and Discussion}

\subsection{Chemistry}

The synthetic route to synthesize desired benzopyrazines has been present in Figure 3. In the first step, the $\alpha$-methyl group of acetophenone was oxidized to carbonyl group by using selenium dioxide. The dicarbonyl intermediate 4 was then reacted without purification with 4-methylbenzene-1,2diamine at room temperature to afford corresponding benzopyrazine (Figure 3). Following the optimized method, a range of novel benzopyrazines has been prepared [29]. ${ }^{1} \mathrm{H}$ NMR spectra of the resulting products showed two regioisomers in $1: 1$ to $1: 0.5$ ratio due to difference in reactivity of C-2 keto and C-3 aldehyde moieties in intermediate 4 . The structure of two regio-isomers were fully characterize by ${ }^{1} \mathrm{H}$ and ${ }^{13} \mathrm{C}$ NMR two dimensional NMR techniques including COSY, NOESY, HSQC, and HMBC. Regio-isomers separation was proved to be difficult in different solvent systems. Only an isomer of 3'-bromo benzopyrazine 6i' was isolated that help to assign the structure of regioisomers from NMR data.

Table 1 shows the data of isomeric mixture $\left(6 n / 6 n^{\prime}\right)$ and Table 2 for isomer $6 i^{\prime}$. Table 1 shows the data of $3^{\prime}$ nitrophenyl benzopyrazine regio-isomers $\left(6 n / 6 n^{\prime}\right)$. The only difference between both structures (I and II) is the position of methyl group (C-6/7) at phenyl ring $\mathrm{B}$. The characteristic signals in both benzopyrazine isomers are C-5, C-6/7, C-8, and $\mathrm{C}-9 / 10$. The structure I shows a broad singlet (brs) for $\mathrm{C}$ 5 proton at $\delta 7.94 \mathrm{ppm}$ while in structure II brs for C-8 proton appears at $\delta 8.03 \mathrm{ppm}$. The HMBC spectrum shows correlation of $\mathrm{C}-5 / \mathrm{I}$ proton with $\mathrm{C}-7, \mathrm{C}-9$, and $\mathrm{C}-11$ and $\mathrm{C}$ 8/II proton with $\mathrm{C}-6, \mathrm{C}-10$, and $\mathrm{C}-11$. In NOESY spectrum, $\mathrm{H}-5 / \mathrm{I}$ correlations with H-7, C-11 and H-8/II with H-6, C-11 are observed. On the other hand, $\mathrm{C}-8 / \mathrm{I}$ and $\mathrm{C}-5 / \mathrm{II}$ protons show doublets (d) at $\delta 8.09$ and $\delta 8.04$ ppm, respectively, in both isomers. HMBC correlations of $\mathrm{C}-8 / \mathrm{I}$ proton with $\mathrm{C}-10$ and $\mathrm{C}-5 / \mathrm{II}$ proton with $\mathrm{C}-9$ are observed. COSY spectrum shows correlations of $\mathrm{H}-8 / \mathrm{I}$ with $\mathrm{H}-7$ and $\mathrm{H}-5 / \mathrm{II}$ with $\mathrm{H}-6$. NOESY spectrum also shows correlations of $\mathrm{H}-8 / \mathrm{I}$ with $\mathrm{H}-7$ and H-5/II with H-6. Characteristic signals of C-7/I and C6/II further confirm the structures of regio-isomers. A combined triplet of doublet (td) appears for both protons at $\delta$ $7.46 \mathrm{ppm}$. HMBC spectrum shows correlation of $\mathrm{C}-7 / \mathrm{I}$ proton with C-5, C-9, C-11 and C-6/II with C-8, C-10 and C11. In NOESY spectrum, H-7/I shows correlation with $\mathrm{H}-8$ and $\mathrm{H}-11$ and $\mathrm{H}-6 / \mathrm{II}$ with $\mathrm{H}-5$ and $\mathrm{H}-11$. Further details of correlation data has been summarized in the Table 1. Moreover, ${ }^{1} \mathrm{H},{ }^{13} \mathrm{C}$ and correlations data of isolated 2-(3'bromophenyl)-7-methylbenzopyrazine $6 \mathrm{i}^{\prime}$ isomer has been summarized in Table 2 which corresponds to isomer (II) data in Table 1.

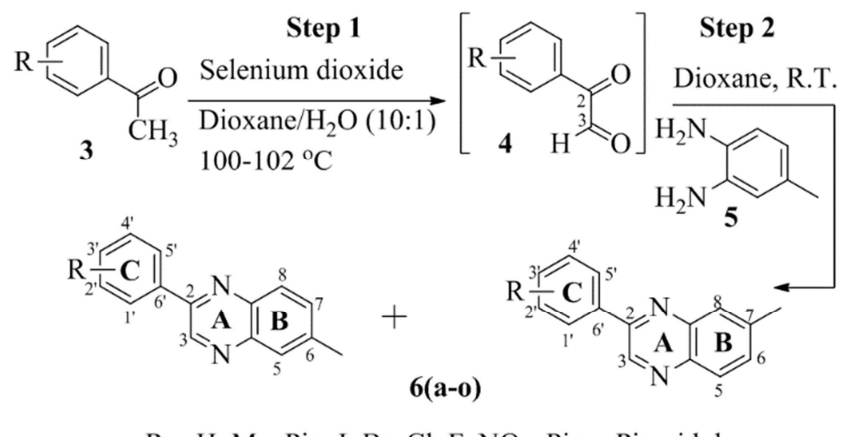

$\mathrm{R}=\mathrm{H}, \mathrm{Me}, \mathrm{Pip}, \mathrm{I}, \mathrm{Br}, \mathrm{Cl}, \mathrm{F}, \mathrm{NO}_{2}$, Pip = Piperidyl

Figure 3. Synthesis of benzopyrazines $6(a-o)$.

Table 1. NMR data of benzopyrazine isomer $6 n / 6 n^{\prime}$.

\begin{tabular}{|c|c|c|c|c|c|c|}
\hline C \# & $\delta_{\mathrm{C}}\left(\mathbf{I} / \mathbf{I I}^{*}\right)$ & $\delta_{\mathrm{H}}$ & Mul. & НВМС & COSY & NOESY \\
\hline $1^{\prime}$ & 137.8 & - & $\mathrm{C}$ & - & - & - \\
\hline 2 & $147.96 / 148.59$ & 9.71 & $\mathrm{C}$ & - & - & - \\
\hline $2^{\prime}$ & $133.65 / 133.56$ & $8.76(\mathrm{~d}, J=7.6 \mathrm{~Hz})$ & $\mathrm{CH}$ & $\mathrm{C}-2, \mathrm{C}-4^{\prime}, \mathrm{C}-6^{\prime}$ & H-3', H-6' & H-3', H-4', H-6', H-3 \\
\hline 3 & $143.62 / 142.79$ & $9.65 / 9.62($ each s) & $\mathrm{CH}$ & $\mathrm{C}-2, \mathrm{C}-10$ & & H-2', H-6' \\
\hline $3^{\prime}$ & 130.82 & $7.88(\mathrm{td}, J=1.6,8.0 \mathrm{~Hz})$ & $\mathrm{CH}$ & $\mathrm{C}-1^{\prime}, \mathrm{C}-5^{\prime}$ & H-2', H -4' & $\mathrm{H}-2^{\prime}, \mathrm{H}-4^{\prime}$ \\
\hline $4^{\prime}$ & $124.82 / 124.70$ & $8.38(\mathrm{~d}, J=8.0 \mathrm{~Hz})$ & $\mathrm{CH}$ & $\mathrm{C}-2^{\prime}, \mathrm{C}-5^{\prime}, \mathrm{C}-6^{\prime}$ & H-3', H -6' & H-3' \\
\hline 5 & $127.69 / 128.51$ & $7.94(\mathrm{~s}) / 8.04(\mathrm{~d}, J=8.8 \mathrm{~Hz})$ & $\mathrm{CH}$ & C-7, C-9, C-11 / C-9 & - / H-6 & H-7, H-11 / H-6, H-11 \\
\hline 6 & 141.34 / 132.91 & $7.46(\operatorname{app~td}, J=1.2,9.6 \mathrm{~Hz})$ & $\mathrm{C} / \mathrm{CH}$ & - / C-8, C-10, C-11 & - / H-5, H-8 & - / H-5, H-11 \\
\hline $6^{\prime}$ & $121.85 / 121.73$ & 9.08 (brs) & $\mathrm{CH}$ & $\mathrm{C}-2, \mathrm{C}-2^{\prime}, \mathrm{C}-4^{\prime}$ & H-2', H-4' & H-2', H-4' \\
\hline 7 & $133.23 / 141.34$ & $7.46($ app td, $J=1.2,9.6 \mathrm{~Hz})$ & $\mathrm{CH} / \mathrm{C}$ & C-5, C-9, C-11 / - & $\mathrm{H}-5, \mathrm{H}-8 /-$ & H-8, H-11 / - \\
\hline 8 & $128.99 / 128.12$ & $8.09(\mathrm{~d}, J=8.4 \mathrm{~Hz}) / 8.03(\mathrm{~s})$ & $\mathrm{CH}$ & C-6, C-10 / C-6, C-10, C-11 & H-7 / - & H-7 / H-11 \\
\hline 9 & $139.73 / 141.11$ & - & $\mathrm{C}$ & - & - & - \\
\hline 10 & $141.6 / 140.08$ & - & $\mathrm{C}$ & - & - & - \\
\hline 11 & 21.39 & $2.59(\mathrm{~s})$ & $\mathrm{CH}_{3}$ & & & H-5, H-7 / H-6, H-8 \\
\hline
\end{tabular}

${ }^{*}$ Regioisomers; app (apparent), brs (broad singlet), mul. Multiplicity. 
Table 2. NMR data of isolated major isomer $6 i^{\prime}$.

\begin{tabular}{lllllll}
\hline $\mathbf{C} \#$ & $\boldsymbol{\delta}_{\mathbf{C}}(\mathbf{I I})$ & $\boldsymbol{\delta}_{\mathbf{H}}$ & Mul. & HBMC & COSY & NOESY \\
\hline $1^{\prime}$ & 138.5 & - & $\mathrm{C}$ & - & - & - \\
2 & 149.33 & $9.71(\mathrm{~s})$ & $\mathrm{C}$ & - & - & - \\
$2^{\prime}$ & 126.34 & $8.33(\mathrm{dd}, J=2.5,8.0 \mathrm{~Hz})$ & $\mathrm{CH}$ & $\mathrm{C}-2, \mathrm{C}-4^{\prime}, \mathrm{C}-6^{\prime}$ & $\mathrm{H}-3^{\prime}$ & $\mathrm{H}^{\prime} 2^{\prime}, \mathrm{H}-3, \mathrm{H}-3^{\prime}$ \\
3 & 142.80 & $9.53(\mathrm{~s})$ & $\mathrm{CH}$ & $\mathrm{C}-2, \mathrm{C}-10$ & - & $\mathrm{H}^{\prime}, \mathrm{H}^{\prime}-6^{\prime}$ \\
$3^{\prime}$ & 131.32 & $7.55(\mathrm{t}, J=3.0 \mathrm{~Hz})$ & $\mathrm{CH}$ & $\mathrm{C}-1^{\prime}, \mathrm{C}-4^{\prime}, \mathrm{C}-5^{\prime}$ & $\mathrm{H}-2^{\prime}, \mathrm{H}-4^{\prime}$ & $\mathrm{H}^{\prime} 2^{\prime}, \mathrm{H}^{\prime} 4^{\prime}$ \\
$4^{\prime}$ & 132.93 & $7.76(\mathrm{ddd}, J=1.0,2.0,8.0 \mathrm{~Hz})$ & $\mathrm{CH}$ & $\mathrm{C}-2^{\prime}, \mathrm{C}-6^{\prime}$ & $\mathrm{H}-3^{\prime}, \mathrm{H}-6^{\prime}$ & $\mathrm{H}^{\prime} 3^{\prime}$ \\
5 & 128.93 & $8.01(\mathrm{~d}, J=8.5 \mathrm{~Hz})$ & $\mathrm{CH}$ & $\mathrm{C}-7, \mathrm{C}-9$ & $\mathrm{H}-6$ & $\mathrm{H}-6$ \\
$5^{\prime}$ & 122.63 & - & $\mathrm{C}$ & - & - & - \\
6 & 132.57 & $7.71(\mathrm{dd}, J=2.0,8.5 \mathrm{~Hz})$ & $\mathrm{CH}$ & $\mathrm{C}-8, \mathrm{C}-10, \mathrm{C}-11$ & $\mathrm{H}-5$ & $\mathrm{H}-5, \mathrm{H}-11$ \\
$6^{\prime}$ & 129.77 & $9.08(\mathrm{t}, J=2.0 \mathrm{~Hz})$ & $\mathrm{CH}$ & $\mathrm{C}-2, \mathrm{C}-2^{\prime}, \mathrm{C}-4^{\prime}, \mathrm{C}-5^{\prime}$ & $\mathrm{H}-2^{\prime}, \mathrm{H}-4^{\prime}$ & $\mathrm{H}-2^{\prime}, \mathrm{H}-3$ \\
7 & 140.72 & - & $\mathrm{C}$ & - & - & - \\
8 & 127.65 & $8.03(\mathrm{brs})$ & $\mathrm{CH}$ & $\mathrm{C}-6, \mathrm{C}-10, \mathrm{C}-11$ & - & $\mathrm{H}-11$ \\
9 & 141.10 & - & $\mathrm{C}$ & - & - & - \\
10 & 139.77 & - & $\mathrm{C}$ & - & - & - \\
11 & 21.36 & $2.58(\mathrm{~s})$ & $\mathrm{CH}$ & & $\mathrm{H}-6, \mathrm{H}-8$ \\
\hline
\end{tabular}

\subsection{Bioactivity}

Benzopyrazines 6(a-o) were screened for their inhibitory activity against ALR2 isolated from calf eyes and ALR1 isolated from calf kidneys. Valproic acid and sorbinil have been used as standards for ALR2 $\left(\mathrm{IC}_{50}=3.14 \pm 0.02 \mu \mathrm{M}\right)$ and ALR1 $\left(\mathrm{IC}_{50}=57.4 \pm 0.89 \mu \mathrm{M}\right)$, respectively [33] The bioactivity results presented in the Table 1 reveal eight compounds which display inhibitory activity against ALR2 which is consider major responsible enzyme for diabetic complications. Among the active molecules 4'-hydoxy 61 $\left(\mathrm{IC}_{50}=1.34 \pm 0.07 \mu \mathrm{M}\right)$ and 3'-bromo $6 \mathrm{i}\left(\mathrm{IC}_{50}=3.48 \pm 0.66\right.$ $\mu \mathrm{M})$ analogues were found to be most active inhibitors for ALR2. Further compounds $6 \mathrm{~g}\left(\mathrm{IC}_{50}=5.85 \pm 1.0 \mu \mathrm{M}\right)$, $6 \mathrm{k}$ $\left(\mathrm{IC}_{50}=10.92 \pm 0.1 \mu \mathrm{M}\right), 6 \mathrm{n}^{\prime}\left(\mathrm{IC}_{50}=8.78 \pm 1.23 \mu \mathrm{M}\right)$, and $6 \mathrm{o}$ $\left(\mathrm{IC}_{50}=16.61 \pm 2.0 \mu \mathrm{M}\right)$ possessed moderate activities while rest of two molecules $6 \mathrm{c}\left(\mathrm{IC}_{50}=66.11 \pm 0.7 \mu \mathrm{M}\right)$ and $6 \mathrm{n}$ $\left(\mathrm{IC}_{50}=30.45 \pm 0.3 \mu \mathrm{M}\right)$ exhibited low activities for ALR2. A limited structure activity relationship (SAR) reveals that variation in inhibitory activities and selectivity of active compounds for ALR2 over ALR1 depends upon the different substituents at phenyl ring $\mathrm{C}$ of benzopyrazines. Compound 61 is having 4'-hydroxy substituent on phenyl ring exhibits highest activity while the compounds $6 \mathrm{k}$ and 60 with 4'substitutents (I and Pip) showed reduced inhibitory activity.
Interestingly, 4'-iodo derivative $6 \mathrm{k}$ with moderate activity $\left(\mathrm{IC}_{50}\right.$ value of $\left.10.92 \pm 1.55 \mu \mathrm{M}\right)$ showed complete selectivity for ALR2. Moreover, the 3'-bromophenyl analogue $6 \mathrm{i}$ showed comparable activity $\left(\mathrm{IC}_{50}=3.48 \pm 0.66 \mu \mathrm{M}\right)$ while 3'-chlorophenyl analogue $6 \mathrm{~g}\left(\mathrm{IC}_{50}=5.85 \pm 0.1 \mu \mathrm{M}\right)$ exhibited slightly lower activity than standard, sorbinil. However, both compounds showed excellent selectivity for ALR2. The 3'-methylphenyl analogue 6c displayed low activity $\left(\mathrm{IC}_{50}=66.11 \pm 0.7 \mu \mathrm{M}\right)$ for ALR2 while moderate activity for ALR1 $\left(\mathrm{IC}_{50}=18.98 \pm 2.0 \mu \mathrm{M}\right)$.

Benzopyrazine $6 \mathrm{a}\left(\mathrm{IC}_{50}=6.43 \pm 1.0 \mu \mathrm{M}\right), 2$-chloro $6 \mathrm{f}$ $\left(\mathrm{IC}_{50}=34.04 \pm 3.0 \mu \mathrm{M}\right)$, and 2'-nitro derivatives $6 \mathrm{~m}\left(\mathrm{IC}_{50}=\right.$ $5.96 \pm 1.55 \mu \mathrm{M})$ were found to be selective inhibitors for ALR1. Compound 60 as dual inhibitor exhibited good activity for ALR1 $\left(\mathrm{IC}_{50}=2.43 \pm 0.87 \mu \mathrm{M}\right)$ and moderate for ALR2 $\left(\mathrm{IC}_{50}=16.61 \pm 2.0 \mu \mathrm{M}\right)$. On the other hand, dual inhibitor 4'-hydroxy 61 analogue was found to be moderately active for ALR1 $\left(\mathrm{IC}_{50}=10.88 \pm 2.68 \mu \mathrm{M}\right)$ while most active and highly selective for ALR2 $\left(\mathrm{IC}_{50}=1.34 \pm 0.07 \mu \mathrm{M}\right)$. Benzopyrazines $6 \mathrm{~b}, 6 \mathrm{~d}, 6 \mathrm{e}, 6 \mathrm{~h}$ and $6 \mathrm{j}$ were found to be completely inactive for both enzymes ALR1 and ALR2. Altogether, the most active compounds 61 and $6 \mathrm{i}$ with good selectivity for ALR2 can serve as potential leads for antidiabetic drug development (Table 3).

Table 3. In vitro ALR2 and ALR2 activities of methyl benzopyrazines 6(a-o).

\begin{tabular}{|c|c|c|c|c|c|c|c|}
\hline \multicolumn{2}{|c|}{ Compounds } & \multirow{2}{*}{$\begin{array}{l}\text { ALR2 } \\
\mathrm{IC}_{50} \pm \mathrm{SEM}^{\mathrm{a}}(\mu \mathrm{M})\end{array}$} & \multirow[t]{2}{*}{ ALR1 } & \multicolumn{2}{|c|}{ Compounds } & \multirow{2}{*}{$\begin{array}{l}\text { ALR2 } \\
\mathrm{IC}_{50} \pm \operatorname{SEM}^{\mathrm{a}}(\mu \mathrm{M})\end{array}$} & \multirow[t]{2}{*}{ ALR1 } \\
\hline & $\mathbf{R}$ & & & & $\mathbf{R}$ & & \\
\hline $6 a$ & $\mathrm{H}$ & N.A. & $6.43 \pm 1^{\mathrm{a}}$ & $6 \mathrm{j}$ & $4^{\prime}-\mathrm{Br}$ & N.A ${ }^{b}$ & N.A. ${ }^{b}$ \\
\hline $6 b$ & $2^{\prime}-\mathrm{Me}$ & N.A. ${ }^{b}$ & N.A. ${ }^{b}$ & $6 \mathrm{k}$ & $4^{\prime}-\mathrm{I}$ & $10.92 \pm 1^{\mathrm{a}}$ & N.A. ${ }^{b}$ \\
\hline $6 c$ & 3'-Me & $66.11 \pm 0.7^{\mathrm{a}}$ & $18.98 \pm 2^{\mathrm{a}}$ & 61 & $4^{\prime}-\mathrm{OH}$ & $1.34 \pm 0.07^{\mathrm{a}}$ & $10.88 \pm 2.68$ \\
\hline $6 \mathrm{~d}$ & $4^{\prime}-\mathrm{Me}$ & N.A ${ }^{b}$ & N.A. ${ }^{b}$ & $6 \mathrm{~m}$ & $2^{\prime}-\mathrm{NO}_{2}$ & N.A ${ }^{b}$ & $5.96 \pm 1.55$ \\
\hline $6 e$ & $3^{\prime}-\mathrm{F}$ & N.A. ${ }^{b}$ & N.A. ${ }^{b}$ & $6 n$ & $3^{\prime}-\mathrm{NO}_{2}$ & $30.45 \pm 3^{\mathrm{a}}$ & N.A. ${ }^{b}$ \\
\hline $6 \mathrm{~g}$ & $3^{\prime}-\mathrm{Cl}$ & $5.854 \pm 1^{\mathrm{a}}$ & N.A. ${ }^{b}$ & \multicolumn{2}{|c|}{ Sorbinil $^{\mathrm{c}}$} & $3.14 \pm 0.02^{\mathrm{a}}$ & - \\
\hline $6 \mathrm{~h}$ & $2^{\prime}-\mathrm{Br}$ & N.A ${ }^{b}$ & N.A. ${ }^{b}$ & \multirow{3}{*}{\multicolumn{2}{|c|}{$\begin{array}{l}\text { Valproic acid } \\
\mathrm{a}=\text { Standard error of mean } \\
\mathrm{b}=\text { Not active } \\
\mathrm{c}=\text { Standards }\end{array}$}} & - & $57.4 \pm 0.89^{a}$ \\
\hline $6 \mathrm{i}$ & & $3.48 \pm 0.66^{\mathrm{a}}$ & N.A. ${ }^{b}$ & & & & \\
\hline $6 i^{\prime}$ & $3^{\prime}-\mathrm{Br}$ & N.A & N.A. & & & & \\
\hline
\end{tabular}




\section{Conclusion}

In conclusion, synthetic methyl benzopyrazines have been evaluated as aldose (ALR2) and aldehyde (ALR1) reductase inhibitors. Compound $6 \mathrm{i}\left(\mathrm{IC}_{50}=3.48 \pm 0.66 \mu \mathrm{M}\right)$ was found selective inhibitor for ALR2, however, 4'-hydroxy benzopyrazine 61 as dual inhibitor $\left(\mathrm{IC}_{50}=10.88 \pm 2.68 \mu \mathrm{M}\right.$ for ALR1) and $\left(\mathrm{IC}_{50}=1.34 \pm 0.07 \mu \mathrm{M}\right.$ for ALR2) shows selectivity more towards ALR2. This study identified some new lead molecules as ALR2 selective inhibitors whose further structural modification may result in good drug candidates.

\section{Conflict of Interest}

There is no conflict of interest any involved in this article.

\section{Supporting Information}

The supporting information includes the experimental data and NMR spectra of benzopyrazines.

\section{Acknowledgements}

We are thankful to H. E. J. Research Institute of Chemistry, International Center for Chemical and Biological Science, University of Karachi, Karachi-Pakistan for financial support. J. Iqbal is thankful to the Organization for the Prohibition of Chemical Weapons (OPCW), The Hague, The Netherlands and Higher Education Commission of Pakistan for the financial support through Project No. 203733/NRPU/R\&D/ 14/520 for the financial support.

\section{References}

[1] Tang, W, Martin, KA and Hwa, J, (2012), Aldose reductase, oxidative stress and diabetic mellitus, Front Pharmacol., 3.

[2] Lorenzi, M, (2007), The polyol pathway as a mechanism for diabetic retinopathy: attractive, elusive, and resilient, J. Diabetes Res., 2007: 1-10.

[3] Kinoshita, J, (1974), Mechanisms initiating cataract formation. Proctor Lecture, Invest. Ophthalmol. Vis., 13: 713-724.

[4] Zhu, C, in Diabetes Mellitus - Insights and Perspectives, INTECH Open Access Publisher, 2013.

[5] El-Kabbani, O, Wilson, DK, Petrash, $\mathrm{M}$ and Quiocho, FA, (1998), Structural features of the aldose reductase and aldehyde reductase inhibitor-binding sites, Mol. Vis., 4: 19-25.

[6] Alexiou, P, Pegklidou, K, Chatzopoulou, M, Nicolaou, I and Demopoulos, VJ, (2009), Aldose reductase enzyme and its implication to major health problems of the 21 st century, Curr. Med. Chem., 16: 734-752.

[7] Qin, X, Hao, X, Han, H, Zhu, S, Yang, Y, Wu, B, Hussain, S, Parveen, S, Jing, C and Ma, B, (2015), Design and synthesis of potent and multifunctional aldose reductase inhibitors based on quinoxalinones, J. Med. Chem., 58: 1254-1267.
[8] Parveen, S, Hussain, S, Qin, X, Hao, X, Zhu, S, Rui, M, Zhang, S, Fu, F, Ma, B and Yu, Q, (2014), Copper-Catalyzed Asymmetric Synthesis and Comparative Aldose Reductase Inhibition Activity of $(+) /(-)-1,2$-Benzothiazine-1, 1-dioxide Acetic Acid Derivatives, J. Org. Chem., 79: 4963-4972.

[9] Saeed, A, Tehseen, Y, Rafique, H, Furtmann, N, Bajorath, J, Flörke, U and Iqbal, J, (2014), Benzothiazolyl substituted iminothiazolidinones and benzamido-oxothiazolidines as potent and partly selective aldose reductase inhibitors, Med. Chem. Comm., 5: 1371-1380.

[10] Stefek, M, Soltesova Prnova, M, Majekova, M, Rechlin, C, Heine, A and Klebe, G, (2015), Identification of Novel Aldose Reductase Inhibitors Based on Carboxymethylated Mercaptotriazinoindole Scaffold, J. Med. Chem., 58: 2649-2657.

[11] Milackova, I, Prnova, MS, Majekova, M, Sotnikova, R, Stasko, M, Kovacikova, L, Banerjee, S, Veverka, M and Stefek, M, (2014), 2-Chloro-1, 4-naphthoquinone derivative of quercetin as an inhibitor of aldose reductase and anti-inflammatory agent, J. Enzyme Inhib. Med. Chem., 30: 107-113.

[12] Maccari, R and Ottanà, R, (2014), Targeting aldose reductase for the treatment of diabetes complications and inflammatory diseases: new insights and future directions, J. Med. Chem., 58: 2047-2067.

[13] Sestanj, K, Bellini, F, Fung, S, Abraham, N, Treasurywala, A, Humber, L, Simard-Dequesne, N and Dvornik, D, (1984), N[[5-(Trifluoromethyl)-6-methoxy-1naphthalenyl]thioxomethyl]-N-methylglycine (Tolrestat), a potent, orally active aldose reductase inhibitor, J. Med. Chem., 27: 255-256.

[14] Ao, S, Shingu, Y, Kikuchi, C, Takano, Y, Nomura, K, Fujiwara, T, Ohkubo, Y, Notsu, Y and Yamaguchi, I, (1991), Characterization of a novel aldose reductase inhibitor, FR74366, and its effects on diabetic cataract and neuropathy in the rat, Metabolism, 40: 77-87.

[15] Poulsom, R, (1986), Inhibition of hexonate dehydrogenase and aldose reductase from bovine retina by Sorbinil, Statil, M79175 and valproate, Biochem. Pharmacol., 35: 2955-2959.

[16] Malamas, MS, Hohman, TC and Millen, J, (1994), Novel Spirosuccinimide Aldose Reductase Inhibitors Derived from Isoquinoline-1, 3-diones: 2-[(4-Bromo-2-fluorophenyl) methyl]6-fluorospiro [isoquinoline-4 (11H), 3'-pyrrolidine]-1, 2', 3, 5'(2H)-tetrone and Congeners. 1, J. Med. Chem., 37: 2043-2058.

[17] Ramirez, MA and Borja, NL, (2008), Epalrestat: an aldose reductase inhibitor for the treatment of diabetic neuropathy, Pharmacother., 28: 646-655.

[18] Yang, Y, Zhang, S, Wu, B, Ma, M, Chen, X, Qin, X, He, M, Hussain, S, Jing, C, Ma, B and Zhu, C, (2012), An Efficient Synthesis of Quinoxalinone Derivatives as Potent Inhibitors of Aldose Reductase, Chem. Med. Chem., 7: 823-835.

[19] Seitz, LE, Suling, WJ and Reynolds, RC, (2002), Synthesis and antimycobacterial activity of pyrazine and quinoxaline derivatives, Journal of medicinal chemistry, 45: 5604-5606.

[20] Guillon, J, Forfar, I, Mamani-Matsuda, M, Desplat, V, Saliege, M, Thiolat, D, Massip, S, Tabourier, A, Léger, J-M and Dufaure, B, (2007), Synthesis, analytical behaviour and biological evaluation of new 4-substituted pyrrolo [1, 2-a] quinoxalines as antileishmanial agents, Bioorg. Med. Chem., 15: 194-210. 
[21] Desplat, V, Moreau, S, Gay, A, Fabre, SB, Thiolat, D, Massip, S, Macky, G, Godde, F, Mossalayi, D and Jarry, C, (2010), Synthesis and evaluation of the antiproliferative activity of novel pyrrolo $[1,2-a]$ quinoxaline derivatives, potential inhibitors of Akt kinase. Part II, J. Enzyme Inhib. Med. Chem., 25: 204-215.

[22] Guillon, J, Grellier, P, Labaied, M, Sonnet, P, Léger, J-M, Déprez-Poulain, R, Forfar-Bares, I, Dallemagne, P, Lemaitre, $\mathrm{N}$ and Péhourcq, F, (2004), Synthesis, antimalarial activity, and molecular modeling of new pyrrolo [1,2-a] quinoxalines, bispyrrolo $[1,2-a]$ quinoxalines, bispyrido $[3,2-\mathrm{e}]$ pyrrolo $[1$, 2-a] pyrazines, and bispyrrolo $[1,2-\mathrm{a}]$ thieno $[3,2-\mathrm{e}]$ pyrazines, J. Med. Chem., 47: 1997-2009.

[23] Zeb, A, Hameed, A, Khan, L, Khan, I, Dalvandi, K, Iqbal Choudhary, M and Z Basha, F, (2014), Quinoxaline derivatives: Novel and selective butyrylcholinesterase inhibitors, Med. Chem., 10: 724-729.

[24] Hameed, A, Zehra, ST, Shah, SJ, Khan, KM, Alharthy, RD, Furtmann, N, Bajorath, J, Tahir, MN and Iqbal, J, (2015), Syntheses, Cholinesterases Inhibition, and Molecular Docking Studies of Pyrido [2, 3-b] pyrazine Derivatives, Chem. Biol. Drug. Des., 86: 1115-1120.

[25] Khan, MS, Munawar, MA, Ashraf, M, Alam, U, Ata, A, Asiri, AM, Kousar, S and Khan, MA, (2014), Synthesis of novel indenoquinoxaline derivatives as potent $\alpha$-glucosidase inhibitors, Bioorg. Med. Chem., 22: 1195-1200.

[26] Shah, CP, Dwivedi, C, Singh, KK, Kumar, M and Bajaj, PN, (2010), Riley oxidation: A forgotten name reaction for synthesis of selenium nanoparticles, Mater. Res. Bull., 45: 1213-1217.
[27] Pohanka, M and Drtinova, L, (2013), Spectrophotometric methods based on 2,6-dichloroindophenol acetate and indoxylacetate for butyrylcholinesterase activity assay in plasma, Talanta, 106: 281-285.

[28] Khalafy, J, Marjani, A and Haghipour, M, (2013), Regioselective synthesis of 3-arylpyrido[2,3-b]pyrazines by reaction of arylglyoxals with 2,3-diaminopyridine, Curr. Chem. Lett., 2: 21-26.

[29] Iqbal, Z, Hameed, S, Ali, S, Tehseen, Y, Shahid, M and Iqbal, J, (2015), Synthesis, characterization, hypoglycemic and aldose reductase inhibition activity of arylsulfonylspiro [fluorene-9, 5'-imidazolidine]-2', 4'-diones, Eur. J. Med. Chem., 98: 127-138.

[30] Ali, S, Saeed, A, Abbas, N, Shahid, M, Bolte, M and Iqbal, J, (2012), Design, synthesis and molecular modelling of novel methyl[4-oxo-2-(aroylimino)-3-(substituted phenyl)thiazolidin-5-ylidene]acetates as potent and selective aldose reductase inhibitors, Med. Chem. Comm., 3: 14281434.

[31] Hayman, S and Kinoshita, JH, (1965), Isolation and Properties of Lens Aldose Redutase, J. Biol. Chem., 240: 877-882.

[32] Costantino, L, Rastelli, G, Gamberini, MC, Vinson, JA, Bose, P, Iannone, A, Staffieri, M, Antolini, L, Del Corso, A, Mura, U and Albasini, A, (1999), 1-Benzopyran-4-one Antioxidants as Aldose Reductase Inhibitors, J. Med. Chem., 42: 1881-1893.

[33] Rees-Milton, KJ, Jia, Z, Green, NC, Bhatia, M, El-Kabbani, O and Flynn, TG, (1998), Arch. Biochem. Biophys., 335: 137139. 